See Article page 281.

\section{Commentary: Never let the truth get in the way of a good story}

\author{
Bahaaldin Alsoufi, MD
}

In this issue of the Journal, Da Silva and colleagues ${ }^{1}$ describe 2 children with Ebstein's anomaly who had initially undergone a neonatal Starnes procedure (right ventricular exclusion with fenestrated tricuspid valve patch and modified Blalock-Taussig shunt) and subsequently underwent takedown of the patch and cone repair of the tricuspid valve plus right ventricular outflow tract obstruction relief, thus converting them to biventricular repair (1 patient at age 5 months) and one-and-a-half ventricular repair ( 1 patient at age 17 months after an intermediary Glenn shunt). The authors concluded that this sequence of initial single ventricle palliation and subsequent tricuspid valve repair is a viable strategy for treating neonates with Ebstein's anomaly and severe heart failure.

Ebstein's anomaly is a heterogeneous complex congenital heart disease that involves the tricuspid valve and the right ventricle, with the presentation varying based on the severity of the disease. Dr José Pedro Da Silva is credited for introducing the cone repair, with reports of excellent early and late outcomes. ${ }^{2}$ Subsequently, many surgeons adopted cone repair as the procedure of choice for Ebstein's anomaly. Nonetheless, the majority of patients who underwent cone repair in the early experience of Da Silva and others were older children and young adults, whereas cone repair in very small children has been rarely described. ${ }^{2,3}$

\footnotetext{
From the Department of Cardiovascular and Thoracic Surgery, University of Louisville School of Medicine, Norton Children's Hospital, Louisville, Ky.

Disclosures: The author reported no conflicts of interest.

The Journal policy requires editors and reviewers to disclose conflicts of interest and to decline handling or reviewing manuscripts for which they may have a conflict of interest. The editors and reviewers of this article have no conflicts of interest.

Received for publication May 24, 2020; revisions received May 24, 2020; accepted for publication May 28, 2020.

Address for reprints: Bahaaldin Alsoufi, MD, Department of Cardiovascular and Thoracic Surgery, University of Louisville School of Medicine, Norton Children's Hospital, 201 Abraham Flexner Way, Suite 1200, Louisville, KY 40202 (E-mail: balsoufi@hotmail.com).

JTCVS Techniques 2020;3:284-5

2666-2507

Copyright (C) 2020 The Authors. Published by Elsevier Inc. on behalf of The American Association for Thoracic Surgery. This is an open access article under the CC BY-NCND license (http://creativecommons.org/licenses/by-nc-nd/4.0/).

https://doi.org/10.1016/j.xjtc.2020.05.028
}

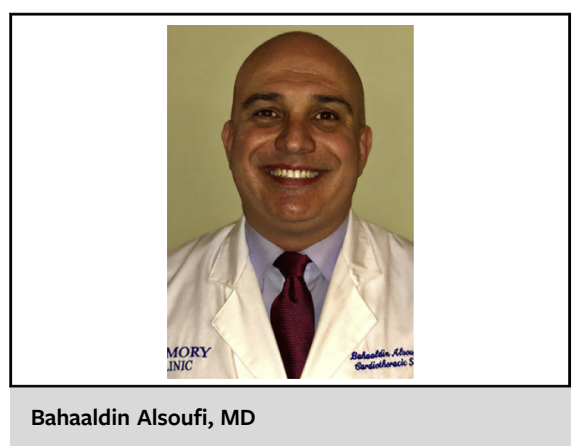

\author{
CENTRAL MESSAGE \\ Management of neonatal Eb- \\ stein's anomaly remains elusive \\ and varies based on presenta- \\ tion, morphology, and experi- \\ ence. A staged Starnes \\ procedure followed by cone \\ repair is a valid strategy in \\ selected patients.
}

The current contribution from Da Silva and colleagues demonstrates the following: (1) cone repair is effective in neonates and small infants with Ebstein's anomaly, analogous to some reports from $\mathrm{Asia}^{4,5}$; and (2) cone repair can be performed following the Starnes procedure. Although tricuspid valve repair has been previously described following the Starnes procedure, this current report might be the first describing cone repair in that setting. ${ }^{6}$ This is valuable information, given the evidence that right ventricular exclusion leads to ventricular regression. ${ }^{7}$ The window for performing biventricular repair after right ventricular exclusion remains unclear.

The issue of whether or not to proceed with a primary neonatal cone repair versus initial single ventricle Starnes procedure followed by cone repair is also unresolved. Although neonatal cone repair might be technically feasible, Ebstein's anomaly involves the right ventricle as well, and the dysfunctional right ventricle might not be able to generate sufficient pressure to open the pulmonary valve in neonates with severe Ebstein's anomaly, favoring initial single ventricle palliation. The criteria for selecting candidates for primary neonatal repair or for eventual biventricular repair remain to be determined and are likely linked to clinical presentation, heart morphology, and institutional experience and philosophy towards this complex 
disease. This report of a staged approach offers a valid strategy in neonates with significant heart failure as a result of severe Ebstein's anomaly.

Although adding another treatment strategy for a difficult problem to the surgeon's armamentarium is a cause for celebration, unfortunately, the reality is less appealing. First, there are substantial variances in the management strategies of neonates with severe Ebstein's anomaly: some centers (eg, Toronto, Melbourne) have reported successful conservative medical management in the majority of patients. ${ }^{8,9}$ When intervention is necessary, some centers are more likely to implement a single ventricle palliation strategy (eg, Los Angeles, Michigan), whereas a few applied primary biventricular repair in the majority of patients (eg, Memphis, Osaka, Taipei). ${ }^{4-6,10,11}$ These variations again highlight the differences in experience and approach to this complex disease and the knowledge gap that exists, prohibiting a consensus uniform tactic for managing these complicated neonates. Second, operative mortality following the diverse treatment strategies of neonatal $\mathrm{Eb}$ stein's anomaly continues to be higher than desired. One of the many contributions of Dr Vaughn Starnes to our field include the single ventricle right ventricular exclusion principle that provided improved survival in these patients; however, mortality continues to be among the highest in our specialty: 5 of $27(19 \%)$ in the experience from Los Angeles (only 13\% with patch fenestration). ${ }^{10}$ Similarly, reported mortality following neonatal tricuspid valve repair for Ebstein's anomaly is high, up to $75 \%$; in the experience of Dr Knott-Craig from Memphis, mortality was $28 \%$, although it was lower in those without pulmonary atresia and those with pulmonary atresia who underwent a right ventricle-to-pulmonary artery conduit. ${ }^{6}$ In a recent review of the Society of Thoracic Surgeons database, tricuspid valve repair was the most common neonatal intervention $(40 \%$; mortality, $34 \%)$, followed by aortopulmonary shunt $(20 \%$; mortality, $17 \%)$ and the Starnes procedure $(9 \%$; mortality, $25 \%)$; again highlighting variations in strategies and continuous high mortality. ${ }^{12}$
In summary, neonatal management of Ebstein's anomaly remains elusive, and proper candidates for conservative medical management and single or biventricular repair are not well identified. Management varies based on morphology, clinical presentation, and institutional experience; however, overall early mortality remains high for all treatment strategies. A staged approach that includes an initial single ventricle Starnes procedure followed by conversion to biventricular repair is feasible and might be considered in selected neonates with intractable heart failure that is not responsive to conservative management.

\section{References}

1. da Silva JP, Viegas M, Castro-Medina M, da Silva LDF. The Da Silva cone operation after the Starnes procedure for Ebstein's anomaly: new surgical strategy and initial results. J Thorac Cardiovasc Surg Tech. 2020;3:281-3.

2. da Silva JP, Baumgratz JF, da Fonseca L, Franchi SM, Lopes LM, Tavares GMP, et al. The cone reconstruction of the tricuspid valve in Ebstein's anomaly. The operation: early and midterm results. J Thorac Cardiovasc Surg. 2007;133: 215-23.

3. Holst KA, Dearani JA, Said S, Pike RB, Connolly HM, Cannon BC, et al. Improving results of surgery for Ebstein anomaly: where are we after 235 cone repairs? Ann Thorac Surg. 2018;105:160-8.

4. Mizuno M, Hoashi T, Sakaguchi H, Kagisaki K, Kitano K, Kurosaki K, et al. Application of cone reconstruction for neonatal Ebstein anomaly or tricuspid valve dysplasia. Ann Thorac Surg. 2016;101:1811-7.

5. Huang SC, Wu ET, Chen SJ, Huang C-H, Shih JC, Chou H-W, et al. Surgical strategy toward biventricular repair for severe Ebstein anomaly in neonates and infancy. Ann Thorac Surg. 2017;104:917-25.

6. Kumar TKS, Boston US, Knott-Craig CJ. Neonatal Ebstein anomaly. Semin Thorac Cardiovasc Surg. 2017;29:331-7.

7. Reemtsen BL, Polimenakos AC, Fagan BT, Wells WJ, Starnes VA. Fate of the right ventricle after fenestrated right ventricular exclusion for severe neonatal Ebstein anomaly. J Thorac Cardiovasc Surg. 2007;134:1406-10.

8. Wald RM, Adatia I, Van Arsdell GS, Hornberger LK. Relation of limiting ductal patency to survival in neonatal Ebstein's anomaly. Am J Cardiol. 2005;96:851-6.

9. Luxford JC, Arora N, Ayer JG, Verrall CE, Cole AD, Orr Y, et al. Neonatal Ebstein anomaly: a 30-year institutional review. Semin Thorac Cardiovasc Surg. 2017;29:206-12

10. Kumar SR, Kung G, Noh N, Castillo N, Fagan B, Wells WJ, et al. Single-ventricle outcomes after neonatal palliation of severe Ebstein anomaly with modified Starnes procedure. Circulation. 2016;134:1257-64.

11. Shinkawa T, Polimenakos AC, Gomez-Fifer CA, Charpie JR, Hirsch JC, Devaney EJ, et al. Management and long-term outcome of neonatal Ebstein anomaly. J Thorac Cardiovasc Surg. 2010;139:354-8.

12. Holst KA, Dearani JA, Said SM, Davies RR, Pizarro C, Knott-Craig C, et al. Surgical management and outcomes of Ebstein anomaly in neonates and infants: a Society of Thoracic Surgeons congenital heart surgery database analysis. Ann Thorac Surg. 2018;106:785-91. 